\title{
Corrosion behaviors of the copper alloy electrodes in ArF excimer laser operation process
}

\author{
Xin Guo ${ }^{1,2}$, Jinbin Ding ${ }^{1,2}$, Yi Zhou ${ }^{1,2}$, and Yu Wang ${ }^{1,2}$ \\ ${ }^{1}$ Academy of Opto-Electronics, Chinese Academy of Sciences, Beijing 100094, China \\ ${ }^{2}$ Beijing Excimer Laser Technology and Engineering Center, Beijing 100094, China \\ (Received 22 October 2017; revised 30 November 2017; accepted 3 January 2018)
}

\begin{abstract}
The corrosion behaviors of the ArF excimer laser copper alloy electrodes were studied. The morphology, composition and impurities were characterized by optical microscope, scanning electron microscopy, electron microprobe and glow discharge mass spectrometer methods. The anode produces the reef, the corrosion pits, the hole layer and the $1-10 \mu \mathrm{m}$ level flake impurity. The cathode produces the particles, the sputtering pits, the element reduce layer and the $1 \mu \mathrm{m}$ level particle impurity. Besides the $\mathrm{Cu}$ element, other elements in the alloy participate in the corrosion: $\mathrm{Al}$ element in the reef is over 1.5 times of the anode, $\mathrm{Zn}$ element in the particles is 1.3 times of the cathode, many trace elements congregate on the copper surface several and even hundreds of times. These elements are responsible to a great degree for the impurities and the rapid energy decline of the long-time idled laser.
\end{abstract}

Keywords: ArF excimer laser; corrosion behavior; electrode; impurity; trace element

\section{Introduction}

The fluoride rare-gas excimer lasers own high output power, large pulse energy and short wave length, and have important application value and prospect in the fields such as semiconductor, photovoltaic, manufacture and medical ${ }^{[1-4]}$. However, the fluorine-containing discharge medium is strongly corrosive to materials ${ }^{[5]}$, which may lead to the deformation of the electrodes ${ }^{[6]}$, the reduction of the fluorine concentration, the generation of impurities and harmful gas ${ }^{[7]}$. It significantly affects the output energy and stability ${ }^{[8-10]}$, limits the performance and application range of the laser.

The electrodes are the most vigorously reacted components with the medium. Studies believe that the cathode is mainly corroded by high current ionized noble gas ion ablation $^{[11]}$, which is mainly a physical reaction ${ }^{[12]}$. The material with strong resistance to sputter such as brass is preferred as the cathode ${ }^{[13]}$. The anode is mainly corroded by F medium, so the material with strong resistance to fluoride, such as $\mathrm{Al}-\mathrm{Cu}$ alloy is preferred ${ }^{[6]}$. The products may form the reef, or spall to intensify the localized corrosion ${ }^{[13]}$. The laser is sensitive to the harmful gas $\mathrm{HF}, \mathrm{O}_{2}, \mathrm{CF}_{4}, \mathrm{SiF}_{4}$, etc $^{[14,15]}$. Sumitani pointed out the addition of only $10 \mathrm{ppm}$ (parts per million) $\mathrm{HF}$ or $\mathrm{SiF}_{4}$ may cause the output energy

Correspondence to: J. B. Ding, Academy of Opto-Electronics, Chinese Academy of Sciences, No. 9, Deng Zhuang South Road, Haidian District, Beijing 100094, China. Email: dinglaser@163.com of ArF excimer laser reduce $10 \%{ }^{[16]}$. The studies on metal and fluorine showed that the reaction includes the fluoride of the elements and the diffusion of the free fluorine ${ }^{[17,18]}$, and the reaction layer is mainly composed of fluoride ${ }^{[19]}$.

However, the above results are mostly based on certain engineering practice and lack of quantitative experimental results, the differences of the components and reaction conditions in different stages and positions are less discussed, the distribution and function of the trace element has not been reported yet. The results are phenomena like the longtime idled laser needs passivation to prevent the rapid decline of its output energy even after its working gas recharged could not be explained, and the influence of some elements on corrosion failed to reach a consensus. Morton thought the cathode corrosion rate had a relative linear relationship with the $\mathrm{Zn}$ content ${ }^{[17]}$, but Timothy believed that the formation of solid products by the $\mathrm{Zn}, \mathrm{P}$ with $\mathrm{F}$ might mitigate the corrosion $^{[6]}$. In fact, the content and the ability of fluoride, sputtering, evaporation of the elements in the alloy are different, the medium concentration and temperature at different positions and in each operation stage also vary, making the corrosion of the electrodes may differ in the reaction degree or even in mechanism ${ }^{[20,21]}$. The integrated circuit manufacture technology and industry has achieved 'grow out of nothing and struggle to perfection', but the research on excimer discharge cavity material system is relatively 
scarce, making this part a limit to the energy improvement and stability of the excimer laser.

In this paper, considering the difference between components and reaction conditions in each stage and position, the morphology and composition of the corroded ArF excimer laser electrodes were studied, the characteristics of the impurities and the distribution of the trace elements were revealed, the influence of the elements was discussed. It will provide theoretical guidance for the material selection, design and corrosion protection of the laser electrodes.

\section{Experiment}

Typical copper alloy was used as electrode material (cathode: H63, anode: QAL9-4). The total pressure of the discharge chamber was around $0.4 \mathrm{MPa}$, whose working gas was $\mathrm{F}_{2}$, $\mathrm{Ar}$ and buffer gas was Ne. The working voltage between the cathode and the anode was $-15 \mathrm{kV}$, and the operation frequency was $100 \mathrm{~Hz}$. After a few months of operation, the electrodes and copper parts were taken out from the discharge chamber and tested quickly to minimize contamination.

The morphology and composition of the electrodes were characterized by scanning electron microscopy with energydispersive spectroscopy (SEM\&EDS, Zeiss, Merlin) and optical microscope $(\mathrm{OM})$. As the fluorides $\mathrm{CuF}_{2}, \mathrm{AlF}_{3}$, $\mathrm{FeF}_{3}, \mathrm{ZnF}_{2}$ were slightly soluble in water, the sample of the subsurface was washed with ultrasonic water. Flakes were found on most parts, but to better preserve the morphology and distinguish with the base, the flakes and their substrate Brewster window $\left(>99 \% \mathrm{CaF}_{2}\right)$ were analyzed together by electron microprobe (EMP, JEOL, JXA-8100) after spraying a $15 \mathrm{~nm}$ conductive carbon film, which affects little on the detection sensitivity. The particles near the cathode were analyzed by SEM\&EDS method after collected by tape. Three places more than $0.2 \mathrm{~cm}$ from the discharge zone were tested to calculate the matrix component. Map scanning was used to reduce the error caused by the unevenness distribution of the elements.

The curved shape and small size of the electrode discharge area, the influence of the sample cutting process both reduce the detect precision of the element. So to study the elements besides $\mathrm{Cu}$, copper parts with smooth surface and suitable size were built into the discharge chamber. Then they were taken out and removed the surface attachment by full air shower, tested by glow discharge mass spectrometer method (GDMS, Thermo Fisher, Element GD).

\section{Results and discussion}

\subsection{The corroded anode}

The discharge area of the corroded anode is mostly covered by the reef, which macroscopically shows pale yellow and green with no metallic luster, as showed in Figure 1(a). The reef is not uniformly distributed, the area without the reef shows metallic luster and is full of corrosion pits. The reef is divided into small areas of several tens of micrometers by a large number of cracks, as showed in Figure 1(b), no microcosmic morphological difference is observed. The $\omega(\mathrm{F}: \mathrm{Al}: \mathrm{Fe}: \mathrm{Cu})$ of the reef is $48.80: 13.47: 11.75: 25.98$ and the $\omega(\mathrm{Al}: \mathrm{Fe}: \mathrm{Cu})$ of the matrix is $8.93: 3.82: 87.25$, so the reef is highly fluorinated and rich in the $\mathrm{Al}, \mathrm{Fe}$ elements. This is because these elements have higher chemical activity than the matrix copper element, they are easier to migrate and accumulate at the reaction interface. The reef may mitigate the corrosion, but its small parts would become impurities if the Pilling-Bedworth stress (caused by lattice mismatch and thermal stress mismatch) or the corrosion effect reached the flaking or evaporation conditions.

The subsurface morphology of the corroded anode is shown in Figure 1(c), with many corrosion pits of 10-20 $\mu \mathrm{m}$ in diameter. The layer occurs when the corrosion of $\mathrm{F}^{-}$ion on the surface turns to the subsurface. Due to the removal of most fluoride in water, the $\omega(\mathrm{F}: \mathrm{Al}: \mathrm{Fe}: \mathrm{Cu})$ of the pits is 3.10:1.17:1.74:93.99, the proportion of $\mathrm{Al}$ and $\mathrm{Fe}$ elements decreases compared to the substrate. This further verifies that the reef contains fluoride of $\mathrm{Al}, \mathrm{Fe}$ elements. The $\omega(\mathrm{F}: \mathrm{Al}: \mathrm{Fe}: \mathrm{Cu})$ of the nondischarge area is 9.69: 15.13: 4.28: 70.90 , indicating that the nondischarge part fluorides and the $\mathrm{Al}$ and $\mathrm{Fe}$ elements accumulate as well. However, the nondischarge area is not corroded by $\mathrm{F}^{-}$ions but by $\mathrm{F}_{2}$ at high temperature, so its fluorination and accumulation degrees of the reactive elements are lower.

Figure 2(a) and Figure 2(b-f) are the cross section morphology and composition distribution of the corroded anode. The reef is about $10-15 \mu \mathrm{m}$ in thickness, the $\mathrm{Al}$ element presents gradient distribution in the range of several microns to the surface, but no composition distribution occurs on a larger scale. Meanwhile, little F element is detected. Under the action of strong electric field and high current density, the vacancy aggregates and metal ions diffuse, so the holes formed within the distance of $60-70 \mu \mathrm{m}$ to the surface. The holes are irregular in shape and vary in size from 1 to 10 level microns, and their composition shows little difference from the matrix.

\subsection{The corroded cathode}

Unlike the anode, the corroded cathode surface presents a metallic luster of copper yellow and contains many sputtering pits, as shown in Figure 3(a). This is because the cathode is mainly corroded by the $\mathrm{Ar}^{+}$ion ablation, little fluoride generates on the surface. Small particles are distributed on the surface of the sputtering pits, as shown in Figure 3(b), which are mainly composed of $\mathrm{Zn}$ and $\mathrm{Cu}$ and sometimes $\mathrm{Al}, \mathrm{Fe}$ elements. The particles may be generated during the short time reversal of the electrode voltage in each 


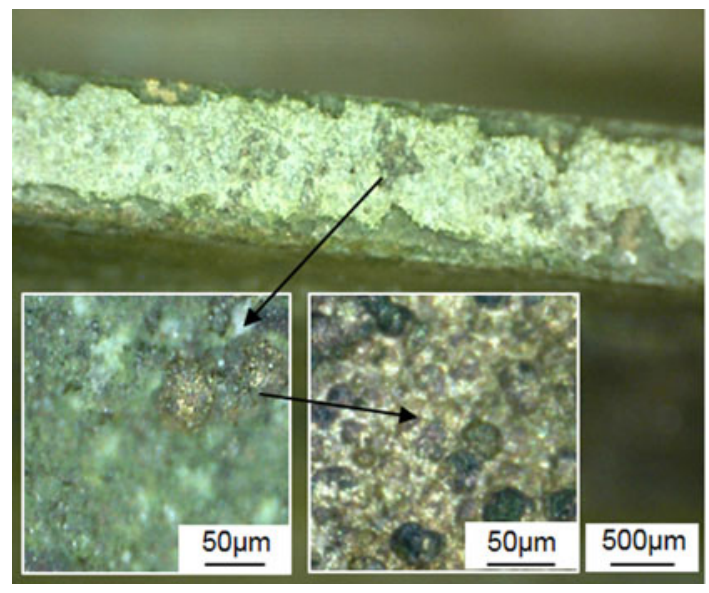

(a)

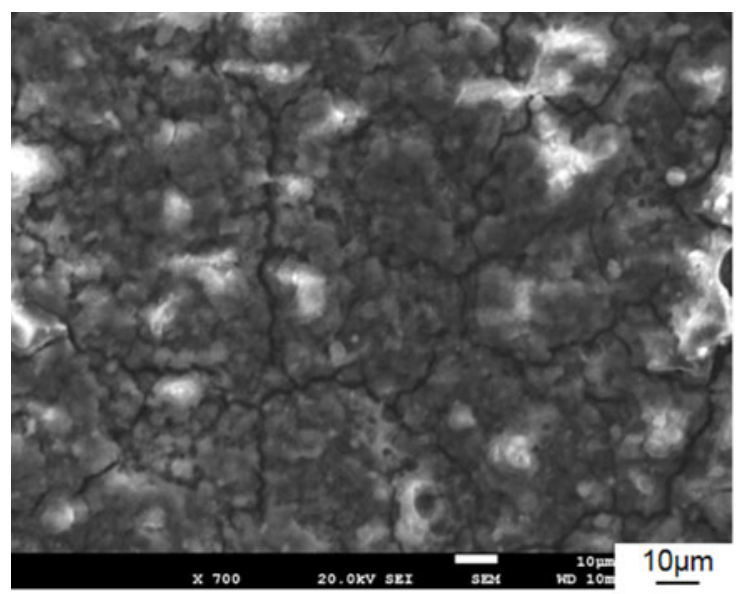

(b)

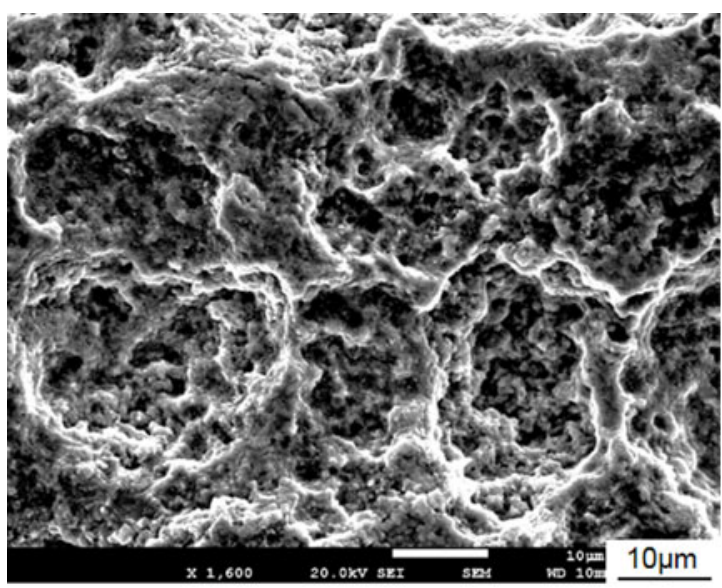

(c)

Figure 1. The morphology of the corroded anode. (a) Surface morphology by OM. (b) Surface morphology by SEM. (c) Subsurface morphology by SEM.

(a)

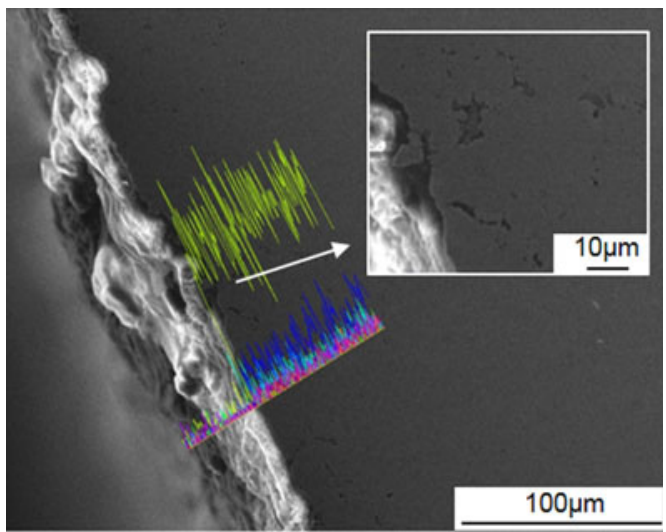

(b)

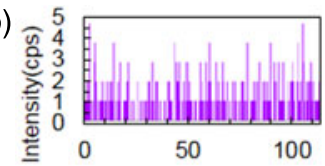

(d)

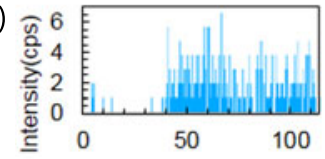

(f)

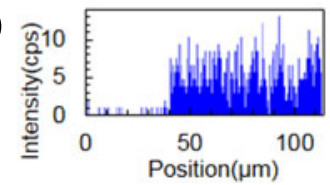

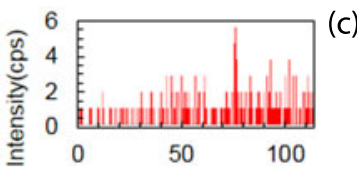

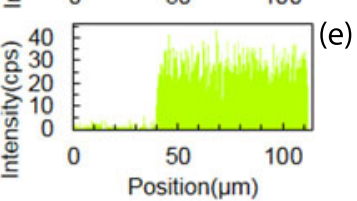

Figure 2. (a) The cross section morphology and (b) C, (c) $\mathrm{O}$, (d) F, (e) $\mathrm{Cu}$, (f) $\mathrm{Al}$ element distributions of the corroded anode.

discharge: Under the effect of electromagnetic fields and particle currents, the sputtering particles that leaving the cathode return to the cathode surface and cool. The
$\omega(\mathrm{Al}: \mathrm{Fe}: \mathrm{Cu}: \mathrm{Zn})$ of cathode surface is 2.19:4.82:47.18:46.61 and the $\omega(\mathrm{Fe}: \mathrm{Cu}: \mathrm{Zn})$ of the matrix is $0.65: 64.15: 35.20$, indicating an apparent aggregation of $\mathrm{Zn}$ elements on the 


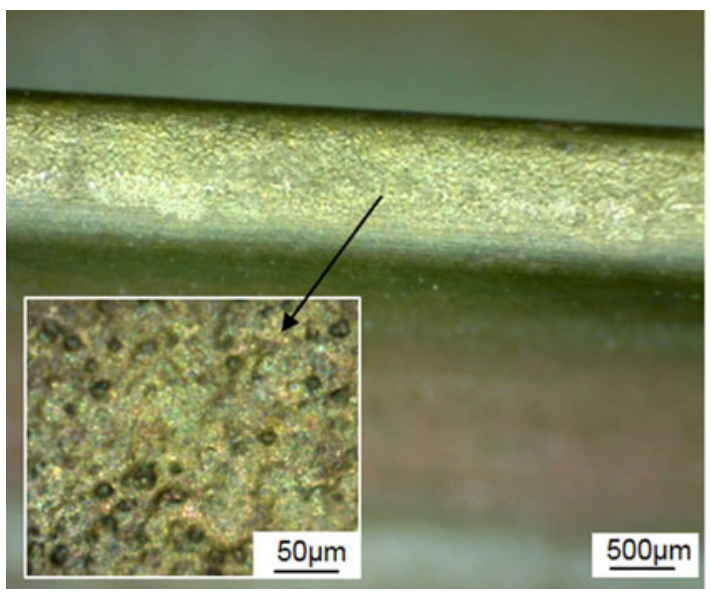

(a)

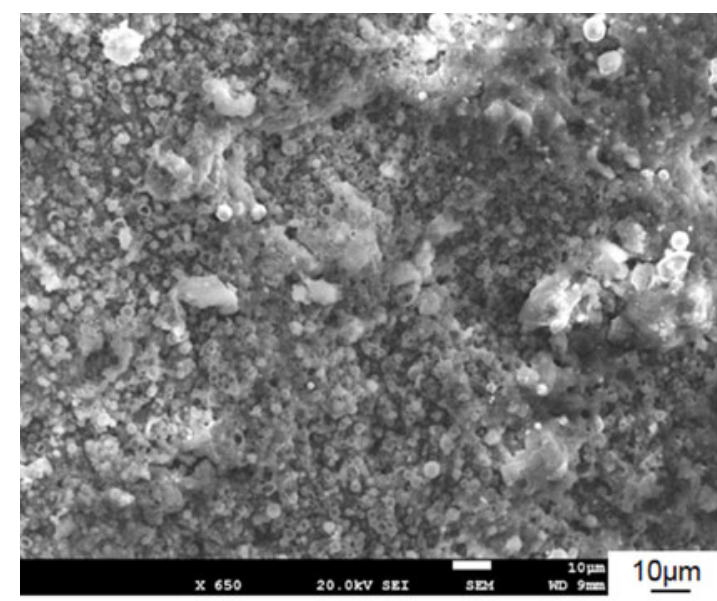

(b)

Figure 3. The surface morphologies of the corroded cathode by (a) OM and (b) SEM.

(a)

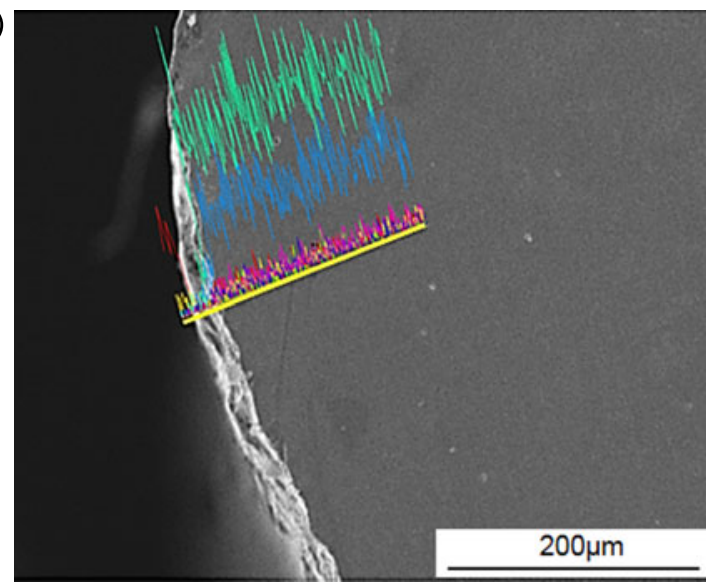

(b)
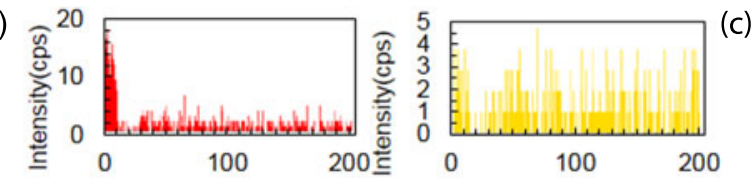

(d)

(f)
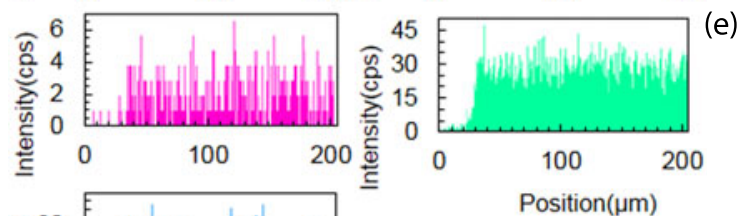

Figure 4. (a) The cross section morphology and (b) C, (c) O, (d) F, (e) Cu, (f) Zn element distributions of the corroded cathode.

cathode surface. This is mainly because the discharge condition has reached the drastic evaporation threshold of $\mathrm{Zn}$ element, which is higher than those of $\mathrm{Cu}$ and $\mathrm{Al}$ elements, the $\mathrm{Zn}$ element migrates significantly and evaporates.

The cross section morphology and composition distribution of the corroded cathode are shown in Figure 4(a) and Figure 4(b-f), under the sputtering pits is the $\mathrm{Zn}$ element content decrease layer. The layer is from a few microns to $10 \mu \mathrm{m}$ in width, which corresponds to the aggregation of $\mathrm{Zn}$ element on the cathode surface, but no obvious changes of other elements such as $\mathrm{Cu}, \mathrm{F}$ element are detected. The composition of the cathode nondischarge area varies, the $\omega(\mathrm{F}: \mathrm{Cu}: \mathrm{Zn})$ close to the discharge area is $6.54: 70.78: 22.68$, but the $\omega(\mathrm{F}: \mathrm{Al}: \mathrm{Cu}: \mathrm{Zn})$ far from it is 15.15:0.76:47.22:37.27, the fluorination degree is lower near the discharge area. This is because the $\mathrm{Ar}^{+}$ion will partially affect the area, reduce the content of fluorine medium and corrode it by sputtering. The cathode temperature is higher than the anode since the loaded high voltage, so its fluoridation is higher.

\subsection{The solid-state impurities}

Parts of the reef may peel off to be flakes and spread over the chamber under the airflow. Figure 5(a) shows the flakes on the Brewster window, it is mainly of the layered structure, and ranging from several microns to tens of microns in size. The main constituents of the impurity are $\mathrm{C}, \mathrm{O}, \mathrm{F}, \mathrm{Al}, \mathrm{Ca}$, $\mathrm{Fe}, \mathrm{Cu}$ elements. $\mathrm{C}$ and $\mathrm{O}$ elements should be introduced in the sampling process since they cannot exist in a stable solid state in the $\mathrm{F}$ medium environment, so they were ignored. The $\omega(\mathrm{F}: \mathrm{Al}: \mathrm{Ca}: \mathrm{Fe}: \mathrm{Cu})$ is $53.50: 6.79: 11.21: 1.19: 27.31$, the proportion of $\mathrm{Cu}, \mathrm{Al}, \mathrm{Fe}$ elements is basically consistent with the reef, and the lamellar structure conforms to the characteristics of exfoliation, so the impurity should be the flakes of the anode. Its aggregation on the window will badly affect the laser beam properties and the window life.

Figure 5(b) shows the morphology of the particles covered near the cathode. It is about $1-2 \mu \mathrm{m}$ in size, and no large particles or laminated structures are found. It contains $\mathrm{Cu}$, 


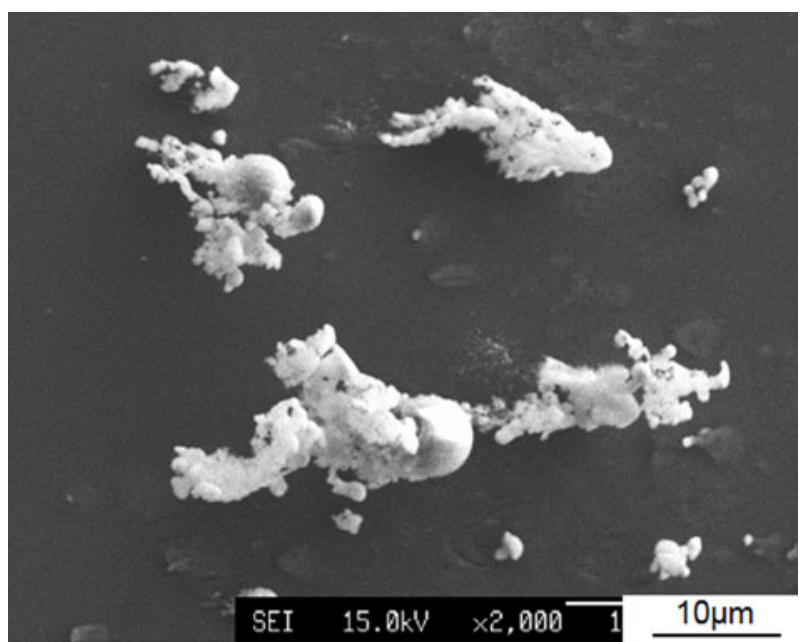

(a)

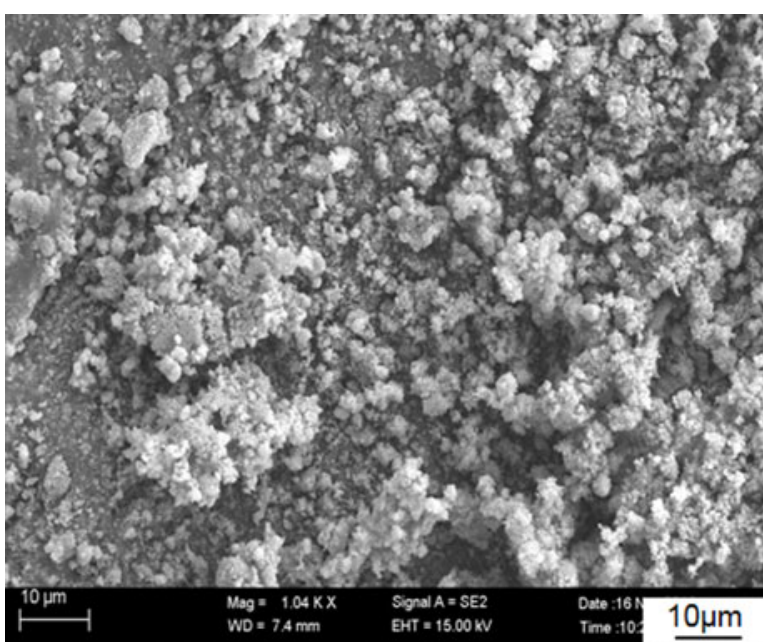

(b)

Figure 5. The morphologies of (a) the flakes generated by the anode and (b) the particles generated by the cathode.

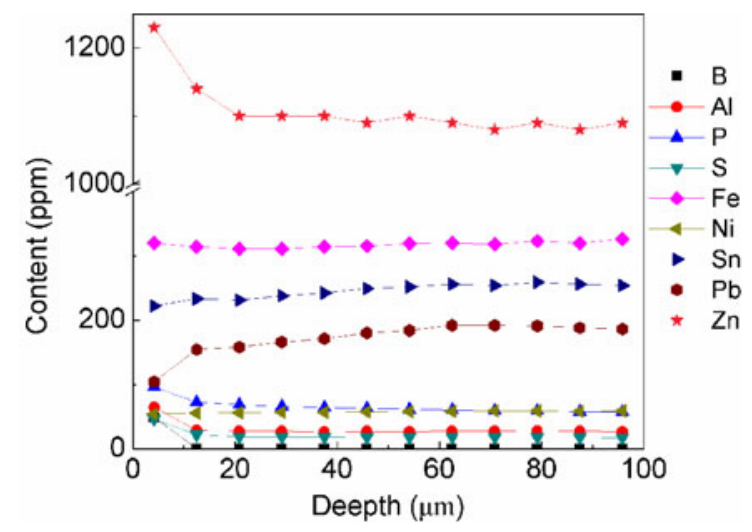

(a)

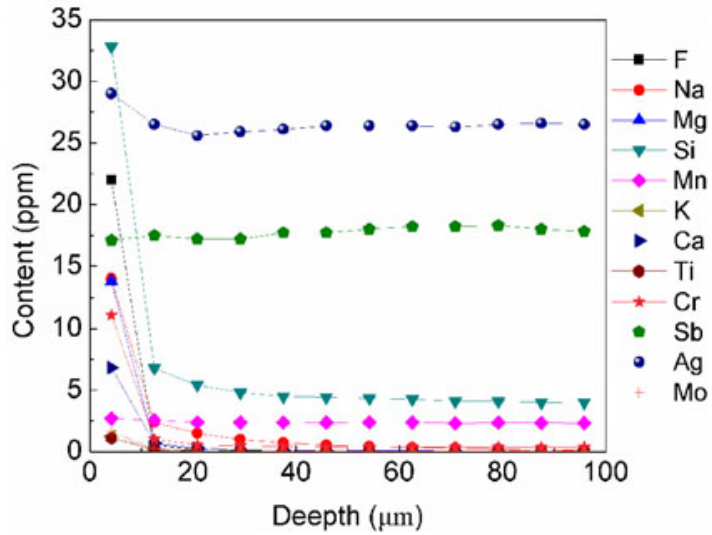

(b)

Figure 6. The trace elements distribution of a copper part. (a) Surface content $>50 \mathrm{ppm}$. (b) Surface content $<50 \mathrm{ppm}$.

$\mathrm{Zn}, \mathrm{Al}, \mathrm{F}, \mathrm{C}$ and $\mathrm{O}$ elements, and the $\omega(\mathrm{F}: \mathrm{Cu}: \mathrm{Zn}: \mathrm{Al})$ is 34.52:37.47:27.88:0.13, the proportion of $\mathrm{Cu}$ and $\mathrm{Zn}$ is higher than the cathode matrix. It indicates that the metallic elements in the particles are mainly from the cathode material, the evaporated $\mathrm{Zn}$ element and the sputtered alloy material react with the fluoride medium to constitute this particle impurity.

\subsection{The trace elements of the copper}

The distribution of trace elements on the surface of copper is shown in Figures 6(a) and 6(b). Most elements gathered near the surface, the content of $\mathrm{Zn}, \mathrm{P}, \mathrm{Al}, \mathrm{S}, \mathrm{Si}$ elements is dozens of times the matrix. The penetration area of the $\mathrm{F}$ element is about $50 \mu \mathrm{m}$. But due to the exposure in the air, serious $\mathrm{F}-\mathrm{O}$ substitution occurred, the content of F element is not high. Some elements such as Ni, Sn, Mn show little difference in the distribution between the surface and the matrix, which suggests they may become surface antiseptic materials. The content of Fe element increases 3\% on the surface, and owns a distribution trend of aggregation - reduction - matrix like $\mathrm{Ag}$ element. The incongruent with the results of Fe element on the electrode surface and the decline of the $\mathrm{Pb}$ element on the surface are uncertain now. They are maybe caused by the difference of alloy components, element diffusion, temperature and product characteristics, which need further study. However, it is clear that most trace elements will diffuse to the surface and participate in the corrosion, and generate the fluoride layer, solid impurities or harmful gases.

\subsection{Analysis and discussion}

The reaction layers and element distribution of the corroded electrodes can be summarized as Figure $7, \omega_{\mathrm{Zn}}$ and $\omega_{\mathrm{Al}}$ 


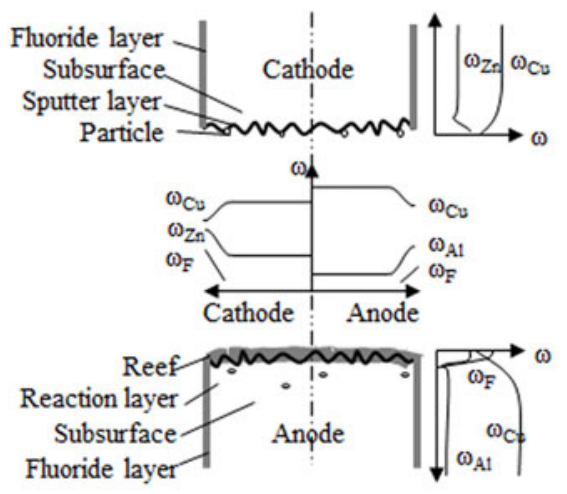

Figure 7. The distribution diagram of reaction layers and elements of the corroded electrodes.

present the kind of elements own similar chemical activity with them. The anode discharge area is corroded to generate the reef, the corrosion pits and the hole layer, and the anode nondischarge area is corroded by $\mathrm{F}_{2}$, its fluoride and reactive element aggregation degree are lower than the reef. And since the anode temperature is lower than the cathode, the fluoride and aggregation degree of the anode nondischarge area is lower than the cathode nondischarge area. The cathode discharge area is corroded to generate the particles, the sputtering pits and the element content decrease layer. In the nondischarge area, the main corrosion medium is $\mathrm{F}_{2}$ not $\mathrm{Ar}^{+}$ion, so the reaction product a fluorinated layer rich in active $\mathrm{Zn}$ element.

Besides copper, most elements in the corrosion, some even show gradient distribution of a small scale. But due to their different dominant reactions and product states, their role is different: the elements whose fluoride is gaseous such as $\mathrm{Si}, \mathrm{C}, \mathrm{H}$ are harmful, no matter they directly react with fluorine medium or sputter before fluoride. The other active elements in the anode diffuse and form the solid fluoride which mitigates the fluoride reaction, but cost the fluoride medium and may generate impurities. The $\mathrm{Zn}$ element in cathode resists sputtering, but its high evaporation aggravates the corrosion of cathode and the consumption of fluoride medium. Of course, the diffusion of $\mathrm{F}$ medium to the matrix and the diffusion of the metal ions to the interface would further increase the corrosion.

Therefore, the reason for the rapid energy decline of the long-time idled laser even after its working gas recharged can be determined. In the long-time idle, the elements on and near the surface of the electrodes react adequately with fluorine medium. In general, the diffusion velocity $\left(V_{d}\right)$ is greater than the interface combination velocity $\left(V_{c}\right)$ in the initial stage, the fluoride layer is linearly thickening over time. But due to its thinner thickness, it affects little on the element diffusion and fluorination. As the fluoride layer becomes thicker, $V_{d}$ is mitigated and gradually smaller than $V_{c}$, the reaction layer would thicken in a parabolic relationship with time. Under its buffer effect, the fluoridation and diffusion are gradually weakened. When the laser operates again, the plasma corrosion of the electrodes begins, and the temperature of the electrodes increases rapidly. Since the fluoride layer of the cathode is destroyed by sputtering and the corrosivity of $\mathrm{F}^{-}$ion is much stronger than $\mathrm{F}_{2}$ for the anode, the diffusion and fluoridation increase rapidly. The reactions consume $\mathrm{F}$ medium more quickly and generate harmful gases rapidly, so the output energy is significantly reduced in a short time even if the working gas is recharged.

The study focusses on the corrosion of the ArF excimer laser electrodes. The corrosion mechanism of the halide rare-gas excimer lasers should be similar, but it is difficult to analyze theoretically how much the quantitative analysis can be generalized. The ArF excimer laser needs many parameters to operate, which may affect the corrosion of the electrodes. Due to the long experimental period and the difficulty in sampling caused by the highly pressured discharge chamber with corrosive gas, the study was carried out with certain set of parameters that the excimer laser operates normally. More studies on the corrosion of other excimer lasers electrodes, the influence of parameters and the behaviors of the trace elements will be required to identify the corrosion behaviors and mechanism of the halide raregas excimer laser electrodes.

\section{Conclusion}

The research on excimer discharge cavity material system is mostly based on engineering practice and lack of quantitative experimental results, the behaviors of the electrode components and some phenomena could not be clearly understood. This paper clarifies the corrosion behaviors and mechanism of the ArF excimer laser electrodes experimentally: the anode discharge area is corroded to generate the reef, the corrosion pits and the hole layer. Parts of the reef may peel off as $1-10 \mu \mathrm{m}$ level flake (the main impurity in the discharge chamber). The cathode discharge area is corroded to generate the particles, the sputtering pits and the element content decrease layer. The strongly evaporated $\mathrm{Zn}$ element intensifies the corrosion of the cathode, together with the sputtered alloy material, they fluorides to constitute the $1 \mu \mathrm{m}$ level particle impurity. Most elements of the electrodes participate in the corrosion. Al element in the reef is over 1.5 times of the anode and $\mathrm{Zn}$ element in the particles is 1.3 times of the cathode, many trace elements congregate on the copper surface several and even hundreds of times. They are responsible to a great degree for the harmful impurities and the phenomena - rapid energy decline of the long-time idled laser. This paper focusses on the corrosion of the ArF excimer laser electrodes, and carried out with one set parameters when the laser operates normally. The corrosion of other excimer lasers electrodes, the influence of parameters on the corrosion and the behaviors of the trace elements need further study. 


\section{Acknowledgement}

This work was supported by the National Natural Science Foundation of China under Grant No. 61705235.

\section{References}

1. Y. Yu, L. You, X. Liang, and X. Fang, Chin. J. Lasers 37, 2253 (2010).

2. J. R. Liu and Z. Y. Hu, Excimer Laser Technology and Application (National Defence Education Press, Beiijing, 2009).

3. N. Benerji, N. Varshnay, D. Ghodke, and A. Singh, Opt. Laser Technol. 84, 72 (2016).

4. X. Liang, B. Bao, and Q. Dai, Acta Photon. Sin. 44, 4 (2015).

5. J. He, S. Lou, and D. Xu, Chin. J. Organic Chem. 36, 6 (2016).

6. S. Timothy, Anodes for fluorine gas discharge lasers, U.S. Patent 7851011B2 (December 14, 2010).

7. H. Shi, J. Zhao, X. Song, P. Sha, Y. Shan, Q. Wang, Y. Zhai, and Y. Zhou, Infrared Laser Eng. 43, 11 (2014).

8. H. Qiu, L. You, Q. Wang, G. Ying, and X. Fang, Chin. J. Quantum Electron. 33, 3 (2016).

9. K. Kakizaki, T. Saito, K. Mitsuhashi, M. Arai, A. Tada, S. Kasahara, T. Igarashi, and K. Hotta, Proc. SPIE 4000, 1397 (2000).
10. P. Zambon, M. Gong, J. Carlesi, G. Padmabandu, M. Binder, K. Swanson, P. Das, and S. Das, Proc. SPIE 4000, 1461 (2000).

11. J. Kardokus, T. Duffley, and W. Partlo, Corrosion resistant electrodes for laser chambers, U.S. Patent 9246298B2 (June 26, 2016).

12. R. Steinberger, J. Duchoslav, M. Arndt, and D. Stifter, Corrosion Sci. 82, 154 (2014).

13. K. Xie, T. Zhang, Z. Wu, X. Liu, and N. Wang, Chin. J. Vac. Sci. Technol. 5, 461 (2014).

14. M. Jursich, W. Vondrasek, R. Brimacombe, and J. Reid, in Conference on Lasers and Electro-Optics (Baltimore, Maryland United States 1990).

15. Q. Lou, Proc. SPIE 1620, 60 (1992).

16. A. Sumitani, S. Andou, T. Watanabe, M. Konishi, S. Egawa, I. Uchino, T. Ohta, K. Terashima, N. Suzuki, T. Enami, and H. Mizoguchi, Proc. SPIE 4000, 1424 (2000).

17. R. Morton, Discharge laser with porous layer covering anode discharge surface, U.S. Patent 2005/0018737A1 (June 27, 2005).

18. H. Qu, H. Chen, and Y. Lang, Constr. Build. Mater. 125, 427 (2016).

19. R. Doerner, D. Nishijima, and T. Schwarz-Selinger, Phys. Scr. 827, 159 (2014)

20. S. Kim and C. Steinbruchel, Solid-State Electron. 43, 1019 (1999).

21. B. Pelissier, H. Fontaine, A. Beaurain, A. Danel, and O. Joubert, Microelectron. Eng. 88, 6 (2011). 